\title{
Optimal Targeting of Advertisement for New Products with Multiple Consumer Segments ${ }^{\dagger}$
}

\author{
VIJAY GANESH HARIHARAN \\ Department of Business Economics \\ Erasmus School of Economics \\ Erasmus University \\ Burgemeester Oudlaan 50 \\ 3000DR Rotterdam, the Netherlands \\ Email: hariharan@ese.eur.nl \\ Phone: +31-10-4082542 \\ DEBABRATA TALUKDAR \\ Department of Marketing \\ School of Managment \\ State University of New York at Buffalo \\ 215E Jacobs Management Center \\ Buffalo, NY 14260, USA \\ Email: dtalukda@buffalo.edu \\ Phone: +1-716 6453243 \\ CHANGHYUN KWON \\ Department of Industrial and Systems Engineering \\ State University of New York at Buffalo \\ 318 Bell Hall \\ Buffalo, NY 14260, USA \\ Email: chkwon@buffalo.edu \\ Phone: +1-716 6454705
}

\footnotetext{
† This paper is based on the first author's dissertation submitted to the State University of New York (SUNY) at Buffalo. The paper has benefited tremendously from comments by Stefan Stremersch, Christophe Van den Bulte, and the IJRM review team.
} 


\title{
Optimal Targeting of Advertisement for New Products with Multiple Consumer Segments
}

\begin{abstract}
Armed with improved targeting technology, firms are increasingly interested in optimizing their advertising dollars through consumer segment-specific targeting, particularly while introducing new products. That task becomes especially important in markets with distinct consumer segments - the early market and the main market - that affect each other's adoption behavior. In this study, in contrast to prior normative studies that assume a single-segment market structure, we derive dynamic optimal advertising and segment-specific targeting strategies for firms facing a two-segment market structure. We allow for mutual demand interactions between the two segments, and for the diffusion parameters, advertising sensitivity, and cost of targeting to differ across the segments. We model the effect of advertising as a logarithmic function that accounts for diminishing marginal returns. Among our key findings: From profit optimization perspective, our two-segment model outperforms the single-segment model under multiple diffusion dynamics contexts - especially for the 'bimodal chasm' and the 'early dip followed by bellshaped' type diffusion patterns - even when the cost of targeting the early market is relatively high. Our numerical analyses indicate that the optimal share of advertisement targeted to the early market segment at launch needs to be much higher than the share of the early market segment in the population. Advertising sensitivity, relative cost of targeting the early market, and the proportion of early market consumers in the population have the greatest effects on the optimal time to transition the targeted advertising spending from the early to the main market segment.
\end{abstract}

Keywords: new product diffusion; advertisement; targeting; social contagion; dynamic optimization 


\section{Introduction}

Firms today have the technology to locate and target individual consumers (Green, 2008; Vascellaro, 2011) and, not surprisingly, such targeting leads to better conversion (Farahat \& Bailey, 2012). For example, during the launch of its new Bluetooth headset in 2013, Motorola approached Klout, a social media analytics firm, to target influential consumers that are passionate about technology and sports (Robehmed, 2013). This helped Motorola to gain 62 million earned impressions. Further, consumers driven to Motorola's webpage through Klout spent about 2.5 times longer than a standard visitor. However, as one would expect, such targeted advertising comes at a higher cost. A recent study sponsored by the Network Advertising Initiative has estimated the cost of targeted advertising to be about 2.7 times more than the cost of regular advertising (Beales, 2009).

With the advent of technology-enabled, more effective but costlier options of finely targeted marketing, a critical challenge faced by business managers when introducing new products is how best to target their advertising dollars. Specifically, this decision context raises several interesting questions that are of importance to both managers and researchers: What should be the optimal advertising and segmentspecific targeting strategies of a firm under different patterns of new product diffusion dynamics? Under what key market conditions should the firm target its advertising spending for its new products based on consumer types rather than mass advertise to the entire market? How do key diffusion dynamics parameters alter the optimal time to transition from targeting the early market segment to the main market segment? ${ }^{1}$ The goal of our paper is to investigate these important and interesting questions from both theoretical and practical perspectives.

Although there exist several normative dynamic models of advertising for new product diffusion (Dockner \& Jorgensen, 1988; Horsky \& Simon, 1983; Krishnan \& Jain, 2006; Teng \& Thompson, 1983; Thompson \& Teng, 1984), the extant literature suffers from the following strong limitations. First, in spite of empirical diffusion studies pointing to multi-segment diffusion dynamics in reality (e.g., Goldenberg et

\footnotetext{
${ }^{1}$ This terminology is adopted from Goldenberg et al. (2002). The early market adopters and the main market adopters are conceptually similar to "influentials" and "imitators" used by Van den Bulte \& Joshi (2007).
} 
al., 2002; Van den Bulte \& Joshi, 2007), none of the prior normative studies derive dynamic optimal advertising strategies using a multi-segment diffusion model. As a consequence, they cannot be used to evaluate the firm's decision to optimally target advertising based on consumer types. Neither could they be used to obtain optimal advertising strategies when the diffusion dynamics follow non-unimodal diffusion patterns, even though such patterns are empirically common (e.g., Goldenberg et al., 2002; Moe \& Fader, 2001). Moreover, the prior studies can generate empirically observed advertising patterns (monotonically decreasing or increase-decrease) as optimal advertising strategies only when they impose unrealistic constraints on the shape of the diffusion dynamics pattern or on the initial advertising spending. For instance, Dockner \& Jorgensen (1988) constrain the adoption pattern to be monotonic to derive monotonically decreasing optimal advertising strategy; in another case, Krishnan \& Jain (2006) derive increase-decrease and monotonically decreasing optimal advertising strategies by constraining the initial advertising to be a priori higher than a particular threshold level.

As highlighted in Table 1, our study contributes to the relevant existing literature in several important ways. It is the first study to develop dynamic optimal advertising and segment-specific targeting strategies for a new product that diffuses simultaneously across two distinct consumer segments - a typical real-world market context. Our diffusion dynamics allows for mutual influence between the segments, and for the diffusion parameters, advertising sensitivity, and cost of targeting to differ across the segments. Our two-segment model structure enables us to analyze firm's optimal advertising and targeting strategies across the four major empirically observed diffusion dynamics patterns - viz., 'unimodal bell-shaped', 'bimodal chasm', 'early dip followed by bell-shaped', and 'exponential decline'.

[Insert Table 1 about here]

\section{Proposed Model}

\subsection{Market's Diffusion Dynamics with Two Segments and Targeted Advertising}

The adoption behaviors of the two segments $(i=1$ refers to the early market, and $i=2$ refers to the main market) are given as follows:

$$
\dot{F}_{1}(t)=\left(1-F_{1}(t)\right)\left(p_{1}+q_{11} F_{1}(t)+q_{12} F_{2}(t)\right)\left[1+\beta_{1} \log (1+\delta(t) u(t))\right], \text { and }
$$




$$
\dot{F}_{2}(t)=\left(1-F_{2}(t)\right)\left(p_{2}+q_{21} F_{1}(t)+q_{22} F_{2}(t)\right)\left[1+\beta_{2} \log (1+(1-\delta(t)) u(t))\right],
$$

where $\dot{F}_{i}(t)$ denotes the rate of adoption of segment $i$ at time $t, F_{i}(t)$ denotes the proportion of consumers in segment $i$ that have adopted at time $t, p_{i}$ denotes the external influence in the adoption behavior of segment $i, q_{i i}$ denotes the within-segment influence in the adoption behavior of segment $i, q_{i j} \forall j \neq i$ denotes the cross-segment influence of segment $j$ on segment $i$ 's adoption, $u(t)$ is the total advertising spending at time $t, 0 \leq \delta(t) \leq 1$ is the proportion of total advertising spending targeted at the early market at time $t$, and $\beta_{i}$ denotes the advertising sensitivity of segment $i$.

Since the early market is more in touch with new developments, its external influence is likely to be higher than that of the main market (i.e., $p_{1}>p_{2}$ ). In line with prior research (e.g., Steffens \& Murthy, 1992; Van den Bulte \& Joshi, 2007), we assume that the main market adopts only through contagion effect (i.e., $\left.p_{2}=0\right){ }^{2}$ The early market will have greater influence on its diffusion process than the main market (i.e., $q_{11}>q_{12}$ ). In addition, the early market will have greater cross-segment influence on the main market than vice versa (i.e., $q_{21}>q_{12}$ ). We define $\theta$ as the proportion of early market adopters in the population. Therefore, the proportion of consumers in the entire market who have adopted at time $t$ is given as $F(t)=\theta F_{1}(t)+(1-\theta) F_{2}(t)$, and the rate of adoption of the entire market at time $t$ is given as $\dot{F}(t)=\theta \dot{F}_{1}(t)+(1-\theta) \dot{F}_{2}(t)$.

We use a logarithmic functional form to incorporate the effect of advertising. A logarithmic functional form allows for diminishing marginal returns to advertising spending, which has been shown to be the case in numerous meta-analyses of advertising effects (e.g., Simon \& Arndt, 1980; Vakratsas \& Ambler, 1999). Moreover, a logarithmic functional form for advertising can be used to derive smooth advertising patterns, which are in line with empirically observed advertising patterns. In contrast, a linear functional form of advertising can yield only a step function as the optimal policy, in which the firm either spends at zero or at maximum during every time period (e.g., Teng \& Thompson, 1983; Thompson $\&$ Teng, 1984). Such extreme values of advertising spending are not observed in empirical contexts.

\footnotetext{
${ }^{2}$ We relax this assumption in one of the diffusion contexts we examine.
} 
Although the time-derivative functional form (e.g., Krishnan \& Jain, 2006) can also be used to obtain smooth advertising patterns, Fruchter \& Van den Bulte (2011) recommend against using such functional form for normative purposes because it has a non-intuitive structure, through which firms can benefit from proportional increases in spending but pay only for levels of spending. We add one to the advertising spending for each segment to avoid logarithm of zero.

\subsection{Firm's Dynamic Optimization Problem}

The objective function of a firm that maximizes its total discounted profit in the presence of a two-segment market structure can be expressed as:

$$
\begin{aligned}
\max _{u(t), \delta(t)} & \Pi_{t}\left(t,\left\{F_{1}(t), F_{2}(t)\right\},\{u(t), \delta(t)\}\right)= \\
& \max _{u(t), \delta(t)} \int_{0}^{T} e^{-\rho t}\left[v(t) N\left\{\theta \dot{F}_{1}(t)+(1-\theta) \dot{F}_{2}(t)\right\}-\{\alpha \delta(t) u(t)+(1-\delta(t)) u(t)\}\right] d t,
\end{aligned}
$$

subject to: $\dot{F}_{1}(t)$ given in Equation $(1), F_{1}(0)=0 ; \dot{F}_{2}(t)$ given in Equation $(2), F_{2}(0)=0$;

$$
u(t) \in[0, U] \forall t \in[0, T] ; \delta(t) \in[0,1] \forall t \in[0, T],
$$

where $v(t)$ denotes the margin at time $t, N$ is the market potential, $T$ is the finite planning horizon, $\rho$ denotes the discount rate during the planning period, and $U$ is the maximum permissible advertising spending. In line with prior studies (e.g., Krishnan \& Jain, 2006; Thompson \& Teng, 1984), we assume that the market adoption process for the new product is complete by the planning horizon $T$. Thus, for the firm's optimization goal above, all its profits stem from consumer adoptions during the finite time period $[0, T]$. Also, in line with prior studies (e.g., Fruchter \& Van den Bulte, 2011; Krishnan \& Jain, 2006), we assume that the margin is exogenous at a monotonically decreasing rate. Specifically, we set $v(t)=$ $v(0) e^{-\mu t}$, where $v(0)$ is the initial margin, and $\mu \geq 0$ is the rate at which the margin decreases.

Although the firm will benefit from faster product diffusion through segment-specific targeted advertising, the parameter $\alpha \geq 1$ in our model reflects the additional costs that such targeting will entail as a trade-off to the increased benefits (Beales, 2009). Specifically, it captures the cost surcharge per monetary unit of advertising spending outlay to target consumers in the early market relative to those in the main market (Iyer et al., 2005). Since we allow the firm's optimal level of advertising spending 
outlays for the early and the main market segments to be $\delta(t) \times u(t)$ and $(1-\delta(t)) \times u(t)$ respectively, the total cost of targeted advertising for the firm is given by $\alpha \delta(t) u(t)+(1-\delta(t)) u(t)$.

Equation (3) represents an optimal control problem that has two state variables $\left(F_{1}(t)\right.$ and $\left.F_{2}(t)\right)$ and two control variables $(u(t)$ and $\delta(t))$. The intrinsic complexity of the firm's optimization problem in Equation (3) makes it impossible to derive closed-form analytical solutions for the control variables. Hence, we numerically solve the optimization problem using discretization. The Hamiltonian and the solution methodology for the numerical optimization are given in Web Appendix A. We prove the existence of an optimal solution for the dynamic optimization problem in Web Appendix B, and discuss the sufficiency conditions in Web Appendix C.

\section{Numerical Results: Insights and Implications}

\subsection{Setting the Scope of the Analyzed Diffusion Patterns}

As noted earlier, a critical shortcoming of prior normative studies that derive dynamic optimal advertising strategies is their single-segment market assumption. As a consequence of that assumption, the underlying diffusion dynamics structure restricts the applicability of the optimal strategies derived by these studies only to market contexts that exhibit the unimodal bell-shaped diffusion pattern. In contrast, our model's two-segment market assumption and the consequent underlying diffusion dynamics structure allow us to derive optimal advertising strategies across a myriad of diffusion patterns. We select the four fundamental diffusion dynamics patterns that are empirically identified in the prior literature.

Specifically, we first consider the diffusion dynamics pattern that has the unimodal bell-shaped trajectory. This pattern is typically observed in markets that face high contagion both within- and between- consumer segments. Prior studies (e.g., Bass, 1969; Bass et al., 1994) have shown that most consumer durables follow this type of diffusion dynamics pattern. The second diffusion dynamics pattern that we consider is the bimodal chasm trajectory. For such diffusion patterns, the contagion is high within each consumer segment, but low between the segments. Therefore, the segments adopt independent of 
each other, leading to a "chasm" in the diffusion pattern (Goldenberg et al., 2002; Moore, 1991). Such pattern of diffusion dynamics is typically observed for high-technology products.

Third, we consider the diffusion dynamics pattern that represents the early dip followed by bellshaped trajectory. In this pattern, the diffusion starts from a higher initial value due to pent-up demand from the early market who adopt independently and rapidly. The main market's reaction to those adoptions is much muted because they mostly imitate other consumers from the main market (Moe \& Fader, 2001; Van den Bule \& Joshi, 2007). This diffusion dynamics pattern is typically observed in case of hedonic products such as music CDs. The fourth diffusion dynamics pattern that we analyze has the exponential decline trajectory. In this pattern, there is high pent-up demand from both the early and the main markets with limited extent of social contagion. This pattern is typically observed in the diffusion of fast moving consumer goods (Du \& Kamakura, 2011) and movies (Moretti, 2011).

Table 2 summarizes the key diffusion dynamics characteristics for the aforesaid four different diffusion patterns. While Table 3 shows the specific diffusion parameters and their respective values that we set to derive the numerical solutions for the dynamic optimization problem for each of the four product diffusion patterns, ${ }^{3}$ Figure 1 plots the respective patterns. We assume that the market potential $(N)$ is 1 million units, planning horizon $(T)$ is 10 years, discount rate $(\rho)$ is 0.2 (Krishnan \& Jain, 2006), ${ }^{4}$ the initial margin $(v(0))$ is $\$ 1$ (Krishnan et al., 1999), rate of decrease in margin is $10 \%$ per year $(\mu=0.1)$ (Van den Bulte \& Joshi, 2007), advertising sensitivities $\left(\beta_{1}\right.$ and $\left.\beta_{2}\right)$ are 0.1 (Dockner \& Jorgensen, 1988), and the maximum permissible advertising spending $(U)$ is $\$ 20,000$.

[Insert Table 2, Table 3 and Figure 1 about here]

In order to compare the derived results between the single-segment and two-segment models, we solve the following dynamic optimization problem for a firm that assumes a single-segment market:

\footnotetext{
${ }^{3}$ We performed a full factorial design using different levels of the various diffusion parameters. Most combinations of diffusion parameters resulted in the four diffusion patterns that we examine. The other theoretically possible diffusion patterns that we obtained are the asymmetric unimodal trajectories with long tails either to the left or to the right. Since these diffusion trajectories are not commonly observed empirically, we do not focus on them in our numerical analyses.

${ }^{4}$ Our substantive results remain robust to discount rate values of 0.05 and 0.1 . Detailed results are available from the authors upon request.
} 


$$
\max _{u_{s}(t)} \Pi_{s}\left(t, F(t), u_{s}(t)\right)=\max _{u_{s}(t)} \int_{0}^{T} e^{-\rho t}\left(v(t) N \dot{F}(t)-u_{s}(t)\right) d t
$$

subject to: $\dot{F}(t)=(1-F(t))(p+q F(t))\left[1+\beta \log \left(1+u_{s}(t)\right)\right], F(0)=0 ; u_{s}(t) \in[0, U] \forall t \in[0, T]$, where $u_{s}(t)$ is the total advertising spending to the entire market at time $t, \beta$ is the advertising sensitivity of the entire market, and $p$ and $q$ are the external and internal influences respectively of the entire market. Equation (4) is an optimal control problem with one state variable $F(t)$ and one control variable $u_{s}(t)$. We set the diffusion parameters of the single-segment model as weighted averages of the parameters across the segments in the two-segment model. Specifically, we set $p=\theta p_{1}+(1-\theta) p_{2}$, and $q=$ $\theta\left(q_{11}+q_{12}\right)+(1-\theta)\left(q_{21}+q_{22}\right){ }^{5}$ We set identical values for the remaining parameters.

\subsection{Dynamic Optimal Advertising and Targeting Strategies}

Figure 2 presents the dynamic optimal advertising and segment-specific targeting strategies $\left(u^{*}(t)\right.$ and $\left.\delta^{*}(t)\right)$ that we derive from numerically solving the two-segment model in Equation (3) and the dynamic optimal advertising strategies $\left(u_{s}^{*}(t)\right)$ that we derive from numerically solving the singlesegment model $^{6}$ in Equation (4) under different diffusion dynamics patterns. We find that the optimal advertising strategies for both single- and two-segment models have an increase-decrease pattern in case of the unimodal bell-shaped diffusion trajectory and a monotonically decreasing pattern for the exponential-decline shaped diffusion trajectory. These patterns are also the most common types of advertising patterns obtained by prior empirical studies (e.g., Lodish et al., 1995), and they are consistent with the following logical intuitions (Fruchter \& Van den Bulte, 2011): "spending should follow the adoption curve" logic leading to the increase-then-decrease pattern, and "get the snowball rolling and then free-ride word-of-mouth" logic leading to the monotonically decreasing pattern.

\section{[Insert Figure 2 about here]}

Although both single-segment and two-segment models yield the same optimal advertising patterns in case of the unimodal bell-shaped and the exponential decline shaped diffusion trajectories, the

\footnotetext{
${ }^{5}$ In Web Appendix D, we show that the two-segment model that ignores heterogeneity across segments reduces to the single-segment model under these conditions.

${ }^{6}$ The numerical solution methodology of the single-segment model is similar to that of the two-segment model and can be obtained from the authors upon request.
} 
advertising patterns differ markedly for the bimodal chasm and the early dip followed by bell-shaped diffusion trajectories. The optimal advertising strategy derived from the single-segment model has an increase-decrease pattern for the bimodal chasm diffusion trajectory and a monotonically decreasing pattern for the early dip followed by bell-shaped diffusion trajectory. In case of the two-segment model, the optimal advertising strategy under both those diffusion trajectories is to maintain a medium level of advertising for a longer duration and then decrease spending. During the period of medium advertising, it is optimal for the firm to shift the targeting of advertising from the early market to the main market when most consumers in the early market have adopted the product. The intuition behind this finding is as follows: shifting the targeting from the early market to the main market while maintaining the advertising level will substitute for the low cross-segment influence that exists between the segments in diffusion dynamics underlying the bimodal chasm and the early dip followed by bell-shaped diffusion trajectories. In addition to differences in the temporal patterns of the derived optimal advertising strategies between the single-segment and two-segment models, we observe differences in the level of advertising spending between the two models. Since the two-segment model allows for an optimal targeting of advertising spending across the segments, we find across all the four diffusion dynamics patterns that it is optimal to start-off with a lower spending level than is the case under the single segment model.

Finally, the optimal targeting strategy $(\delta(t))$ in the two-segment model sheds insights into the optimal allocation of advertising spending to the early versus the main markets during each time period throughout the diffusion process. We find that the optimal targeting strategy follows a decrease-increase pattern across all the four diffusion dynamics patterns, with a higher share of advertising targeted to the early market during the initial periods. Such strategy not only accentuates the intrinsic tendency of the early market to lead the adoption process, but also kick starts the diffusion process of the main market through the cross-segment influence.

\subsection{Targeted Versus Mass-Advertising Strategy}

Given the empirical reality that many markets exhibit a two-segment market structure as well as higher costs for targeted advertising, a naturally important question for firms is: Under what market 
conditions does it make economic sense to advertise to the entire market using mass-media versus to target specific segments? Therefore, we compare the profits of the two-segment model to that of a model in which the firm ignores the reality of a two-segment market structure and derives the advertising strategy assuming a single-segment market.

We calculate the maximum net present value (NPV) for the two-segment model, $\widehat{\Pi}_{t}^{t}\left(t,\left\{F_{1}(t), F_{2}(t)\right\},\left\{u^{*}(t), \delta^{*}(t)\right\}\right)$, by substituting the optimal solutions of the two-segment model $u^{*}(t)$ and $\delta^{*}(t)-$ in Equation (3) as follows:

$$
\begin{aligned}
& \widehat{\Pi}_{t}^{t}\left(t,\left\{F_{1}(t), F_{2}(t)\right\},\left\{u^{*}(t), \delta^{*}(t)\right\}\right) \\
&=\int_{0}^{T} e^{-\rho t}\left[\begin{array}{c}
v(t) N\left\{\theta \dot{F}_{1}\left(t, u^{*}(t), \delta^{*}(t)\right)+(1-\theta) \dot{F}_{2}\left(t, u^{*}(t), 1-\delta^{*}(t)\right)\right\} \\
-\left\{\alpha\left(\delta^{*}(t) u^{*}(t)\right)+\left(1-\delta^{*}(t)\right) u^{*}(t)\right\}
\end{array}\right] d t
\end{aligned}
$$

where $\dot{F}_{1}\left(t, u^{*}(t), \delta^{*}(t)\right)$ and $\dot{F}_{2}\left(t, u^{*}(t), 1-\delta^{*}(t)\right)$ are the rates of adoption of the segments at optimal values of advertising and targeting. We obtain the NPV for the firm that assumes a single-segment market structure in a market that consists of two-segments by substituting the optimal solution of the singlesegment model $\left(u_{s}^{*}(t)\right)$ in Equation (3) as follows:

$$
\begin{aligned}
\widehat{\Pi}_{t}^{s}\left(t,\left\{F_{1}(t), F_{2}(t)\right\},\left\{u_{s}^{*}(t), \theta\right\}\right) \\
\quad=\int_{0}^{T} e^{-\rho t}\left[v(t) N\left\{\theta \dot{F}_{1}\left(t, u_{s}^{*}(t), \theta\right)+(1-\theta) \dot{F}_{2}\left(t, u_{s}^{*}(t), 1-\theta\right)\right\}-u_{s}^{*}(t)\right] d t
\end{aligned}
$$

In Equation (6), we assume that the firm ignoring the two-segment market structure allocates advertising to the segments proportional to their segment sizes. The difference between the NPVs is given as follows:

$$
\Delta \pi \equiv \widehat{\Pi}_{t}^{t}\left(t,\left\{F_{1}(t), F_{2}(t)\right\},\left\{u^{*}(t), \delta^{*}(t)\right\}\right)-\widehat{\Pi}_{t}^{s}\left(t,\left\{F_{1}(t), F_{2}(t)\right\},\left\{u_{s}^{*}(t), \theta\right\}\right) .
$$

We evaluate the relative NPV performance of the two models under two key market conditions related to the early market: viz., the relative cost of targeting the early market $(\alpha)$ and the relative size of the early market $(\theta)$. We allow $\alpha$ to vary from 1 to 3 , in line with empirically observed values (Beales, 2009). For $\theta$, we set the range from 0.1 to 0.5 . For each of our four specific diffusion dynamics patterns, the shaded areas in Figure 3 show the combinations of $\alpha$ and $\theta$ values under which the two-segment model generates greater NPV than the single-segment model (i.e., $\Delta \pi>0$ ). 
The two-segment model performs better across all the four diffusion dynamics patterns if the cost of targeting the early market is lower. At higher relative costs of targeting (i.e., $\alpha>1$ ), the two-segment model performs better if the early market is relatively smaller in size. A novel and important insight evident from Figure 3 is the dominant performance by the two-segment over the single-segment model when the diffusion dynamics pattern follows either the bimodal chasm or the early dip followed by bellshaped trajectory, even at higher costs of targeting the early market. Taken together, the shaded regions in Figure 3 point to significant economic opportunity costs that firms will incur under many realistic market conditions if they use the single-segment model over the two-segment model for their dynamic optimal advertising strategy during new product diffusion process.

[Insert Figure 3 about here]

\subsection{Effects of Diffusion Parameters on the Optimal Targeting Strategy}

A key element of the optimal solutions under the two-segment model is the optimal time to transition more of the targeted advertising from the early to the main market. We refer to this as the target transition time. Prior studies (e.g., Horsky \& Simon, 1983; Mahajan \& Muller, 1998) have identified conditions in which it is better for the firms to target the early versus the main market throughout the diffusion process. However, they have not identified the target transition time. An interesting question from the perspective of both researchers and managers is how the target transition time is affected by market conditions in the form of the parameters of the underlying diffusion dynamics.

To shed insights into that question, in lieu of comparative static analysis due to the absence of closed form solutions for the optimal advertising strategy, we conduct a comprehensive numerical analysis over the following parameter values: $p_{1} \in\{0.1,0.2\}, q_{11} \in\{0.2,0.3\}, q_{12} \in\{0.02,0.04\}, p_{2}=0$, $q_{21} \in\{0.08,0.16\}, q_{22} \in\{0.3,0.4\}, \theta \in\{0.2,0.3\}, \alpha \in\{2,3\}, \beta_{1} \in\{0.1,0.2\}$, and $\beta_{2} \in\{0.1,0.2\}$. The above parameter values yield $2^{9}=512$ market contexts. We obtain the optimal advertising and targeting strategies derived from the two-segment model for each of the above market contexts. 
Across all the market contexts in the numerical analysis, the optimal advertising strategy follows either an increase-decrease pattern or a monotonically decreasing pattern, and the optimal targeting strategy follows a decrease-increase pattern. We find that $\delta$ at $t=0$ is greater than $\theta$ across all the market contexts, and the mean difference between $\delta$ and $\theta$ at $t=0$ is 0.4 . This indicates that, on an average across all the numerically analyzed market contexts, the optimal share of advertisement targeted to the early market segment at launch is about 40 percentage points higher than the share of the early market segment in the population. As noted earlier, such higher advertising spending targeted to the early market at launch not only accelerates the diffusion process within the early market, but also kick starts the diffusion process within the main market through the cross-segment influence.

To examine how various diffusion parameters influence the target transition time, we estimate the following linear regression model using data from the 512 market contexts:

$$
\tau=c_{1} p_{1}+c_{2} q_{11}+c_{3} q_{12}+c_{4} q_{21}+c_{5} q_{22}+c_{6} \theta+c_{7} \alpha+c_{8} \beta_{1}+c_{9} \beta_{2}+\epsilon,
$$

where $\tau$ denotes the target transition time obtained from the numerical analysis. We operationalize $\tau$ as the point in the optimal targeting strategy curve, $\delta(t)$, at which it is optimal for the firm to allocate equal shares of advertising spending to the early market and the main market (i.e., $\delta(\tau)=0.5$ ). A smaller (larger) value of the target transition time, $\tau$, thus indicates that it is optimal for the firm to shift the targeting of its advertising from more on the early market to more on the main market earlier (later) in the diffusion process. We scale the variance of each independent variable in Equation (8) to one in order to obtain standardized parameter estimates. ${ }^{7}$

The standardized parameter estimates are given in Table 4. Most parameter estimates are significant at the 0.001 level $\left(\operatorname{adj}-R^{2}=0.854\right)$. The estimation results show that the target transition time decreases with higher external influence of the early market $\left(c_{1}=-0.106 ; p<0.001\right)$. Since the early market is more likely to adopt independently in markets with high external influence, advertising is more useful to persuade the main market. The results $\left(c_{2}=0.102 ; p<0.001 ; c_{5}=-0.050 ; p=0.003\right)$ also show

\footnotetext{
${ }^{7}$ Note that we cannot estimate an intercept in a model in which the variance of the independent variables are scaled.
} 
that it is optimal to target the early market (the main market) for a longer duration if the within-segment influence of the early market (the main market) is higher.

\section{[Insert Table 4 about here]}

Although the cross-segment influence of the early market to the main market $\left(q_{21}\right)$ has a significant positive effect on the target transition time $\left(c_{4}=0.059 ; p=0.001\right)$, the effect of the crosssegment influence of the main market to the early market $\left(q_{12}\right)$ is insignificant $\left(c_{3}=-0.007 ; p=0.660\right)$. This again underscores the importance of targeting the early market, since this segment's intrinsic role in "triggering" the diffusion process enables its cross-segment influence to play a more effective role in accelerating the diffusion process. In line with the finding of Mahajan \& Muller (1998), the target transition time increases with greater proportion of the early market consumers in the population $\left(c_{6}=\right.$ $0.380 ; p<0.001)$. However, it decreases with higher relative cost of targeting the early market $\left(c_{7}=-\right.$ $0.455 ; p<0.001)$.

Further, the target transition time depends on the advertising sensitivities of both segments. Specifically, it is optimal to transition from the early market to the main market later (sooner) in the diffusion process when the advertising sensitivity of the early market (the main market) is higher $\left(c_{8}=\right.$ $0.675 ; p<0.001$, and $\left.c_{9}=-0.149 ; p<0.001\right)$. This is because a higher advertising sensitivity of the early market (the main market) indicates that an increase in advertising spending for the early market (the main market) will be more effective in accelerating the diffusion process.

In terms of the relative effects of various diffusion parameters on the target transition time, we find that advertising sensitivity of the early market plays the greatest role, followed by the relative cost of targeting the early market, and the proportion of the early market consumers in the population.

\section{Conclusion}

Armed with improved targeting technology, firms are increasingly interested in optimizing their advertising dollars through consumer segment-specific targeting, especially while introducing new products. Systematic empirical evidence also shows the existence of a two-segment market structure in 
the form of early versus main market segments in the diffusion dynamics of many new products (e.g., Goldenberg et al., 2002; Van den Bulte \& Joshi, 2007). However, conspicuously absent from the existing literature are models of normative dynamic advertising and targeting strategies during new product diffusion under such two-segment market structure. The goal of our study is to address this important gap and limitation in the existing literature. In this study, we derive optimal advertising strategies and segment-specific targeting strategies for the four major patterns of diffusion dynamics that have been typically observed across a multitude of product classes.

Numerical analyses of our normative model generate several important insights for both researchers and managers interested in firms' dynamic optimal advertising strategy for new products. First, from profit optimization perspective, the two-segment model outperforms the single-segment model under multiple diffusion dynamics contexts - especially for the bimodal chasm and the early dip followed by bell-shaped diffusion patterns - even when the cost of targeting the early market is relatively high. With evolving more cost-effective targeting technology, the economic opportunity cost from foregone profit optimization will thus only get bigger if firms continue to base their advertising strategy under the premise of a single-segment market structure when a two-segment market structure exists in reality.

Second, in case of diffusion dynamics patterns that follow the bimodal chasm and the early dip followed by bell-shaped trajectories, although firms can start with a medium level of advertising at launch, they should not lower the spending during the first dip in the diffusion process. During the chasm or the dip in the diffusion process, firms should stop targeting the early market and focus on the main market in order to compensate for the lower cross-segment influence that exists between the segments. Third, we find that on an average across all numerically analyzed market contexts, the optimal share of advertisement targeted to the early market segment at launch is about 40 percentage points higher than the share of the early market segment in the population. Fourth, managers should especially focus on the advertising sensitivity of the early market, the relative cost of targeting the early market, and the proportion of the early market in the population to decide when to transition more of the advertising spending share from the early to the main market segment. 
It is relevant to note that our model can be applied to both within and across country settings as long as the new product diffusion process occurs simultaneously across multiple segments with crosssegment influences. For instance, the extant empirical research (e.g., Putsis et al., 1997) suggests that consumers in some countries not only adopt new products faster than their peers in other countries but also exert asymmetric influence on their peers' adoption process.

While our study sheds several new and important insights into firms' dynamic optimal advertising and targeting strategies in many market contexts, it also underscores several complementary directions in need of future research. One such direction would be to derive the optimal advertising strategies after incorporating competition in our two-segment model with demand interactions. Another direction would be to include price in the optimization model and derive joint optimal pricing and advertising strategies in a unified framework. 
Figure 1: Plots of the Four Diffusion Patterns Analyzed in this Study

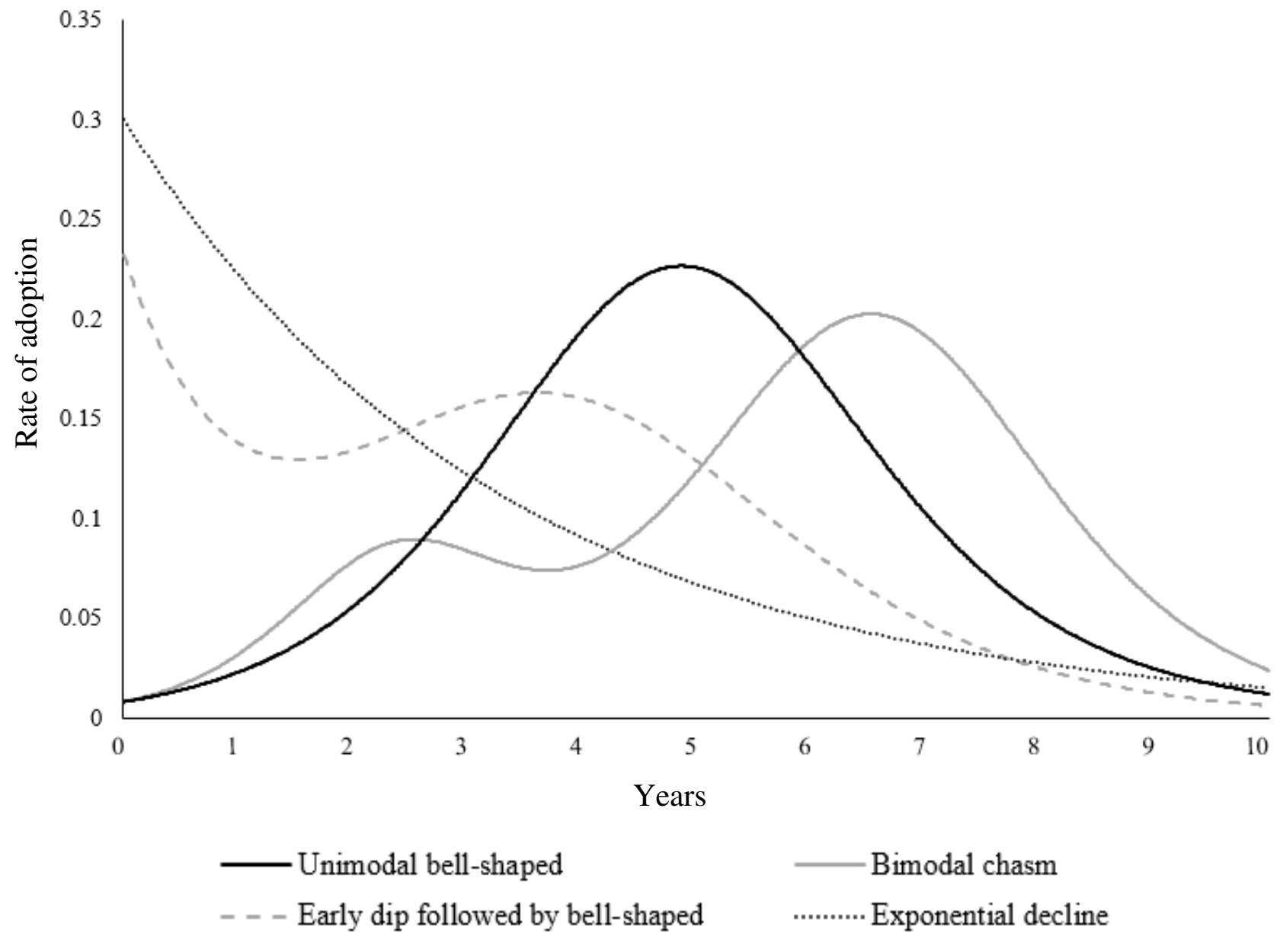


Figure 2: Optimal Advertising and Targeting Strategies
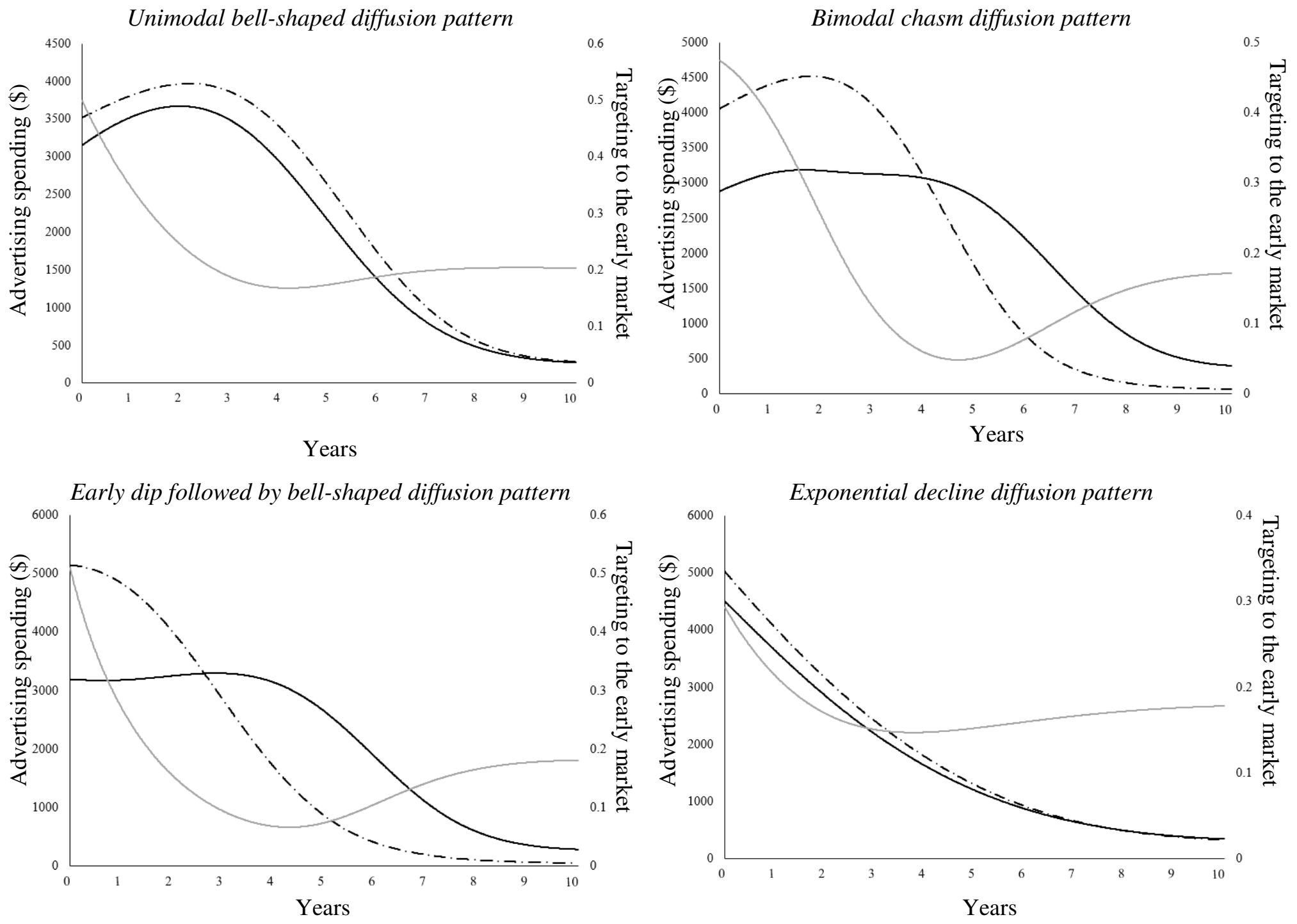

Note: — $\quad$ Optimal advertising strategy from the two-segment model $\left(u^{*}(t)\right)$

Optimal targeting strategy from the two-segment model $\left(\delta^{*}(t)\right)$

- - Optimal advertising strategy from the single-segment model $\left(u_{s}^{*}(t)\right)$ 
Figure 3: Conditions under which the Two-Segment Model Outperforms the Single-Segment Model
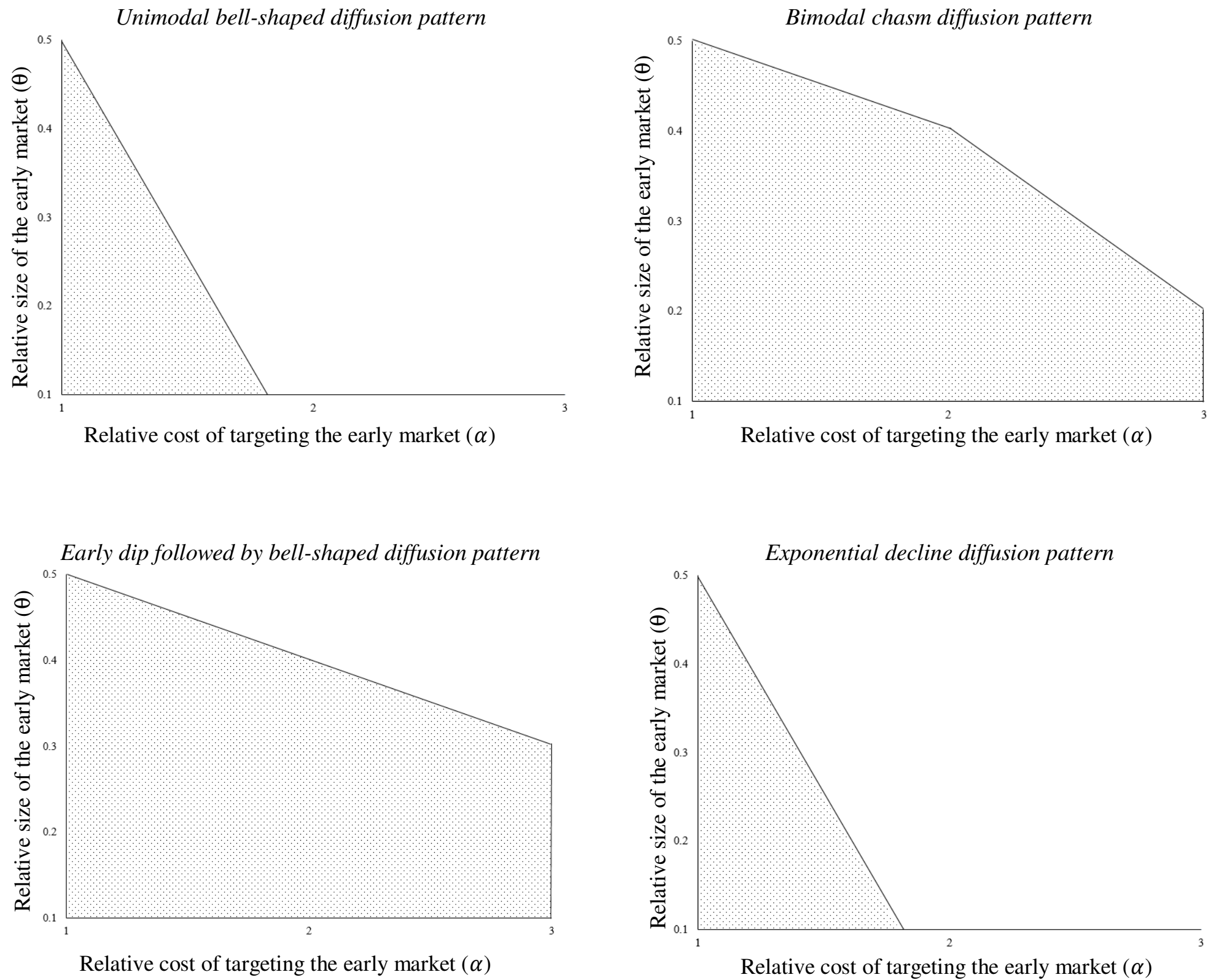

Note: The shaded regions denote the conditions under which the two-segment model outperforms the single-segment model in terms of net present value. 
Table 1: Scope of Prior Studies that Derive Dynamic Optimal Advertising Strategies for New Product Diffusion and Our Study

\begin{tabular}{|c|c|c|c|c|c|c|}
\hline Study & $\begin{array}{l}\text { Number of } \\
\text { segments }\end{array}$ & Diffusion pattern(s) & $\begin{array}{l}\text { Advertising } \\
\text { functional form }\end{array}$ & $\begin{array}{l}\text { Advertising } \\
\text { affects }\end{array}$ & $\begin{array}{l}\text { Price/cost/margin } \\
\text { function(s) }\end{array}$ & Optimal advertising pattern $(s)$ \\
\hline $\begin{array}{l}\text { Horsky \& Simon } \\
\text { (1983) }\end{array}$ & \multirow{5}{*}{ One } & Unimodal & Logarithmic & $\begin{array}{l}\text { Only the external } \\
\text { influence of the } \\
\text { entire market }\end{array}$ & $\begin{array}{l}\text { Constant or decreasing } \\
\text { margin }\end{array}$ & Monotonically decreasing \\
\hline $\begin{array}{l}\text { Teng \& Thompson } \\
\text { (1983) }\end{array}$ & & Unimodal & Linear & \multirow{4}{*}{$\begin{array}{l}\text { Both external } \\
\text { and internal } \\
\text { influences of the } \\
\text { entire market }\end{array}$} & $\begin{array}{l}\text { Constant prices; } \\
\text { decreasing cost }\end{array}$ & Min-max-min \\
\hline $\begin{array}{l}\text { Thompson \& Teng } \\
\text { (1984) }\end{array}$ & & Unimodal & Linear & & $\begin{array}{l}\text { Price is modeled as a } \\
\text { control variable with } \\
\text { decreasing cost. It is } \\
\text { optimal to } \\
\text { monotonically } \\
\text { decrease or increase } \\
\text { then decrease prices. }\end{array}$ & Min-max-min \\
\hline $\begin{array}{l}\text { Dockner \& } \\
\text { Jorgensen (1988) }\end{array}$ & & Monotonic & Logarithmic & & $\begin{array}{l}\text { Constant prices; } \\
\text { decreasing cost }\end{array}$ & $\begin{array}{l}\text { - Monotonically increasing } \\
\text { - Monotonically decreasing }\end{array}$ \\
\hline $\begin{array}{l}\text { Krishnan \& Jain } \\
\text { (2006) }\end{array}$ & & Unimodal & Time-derivative & & $\begin{array}{l}\text { Constant or decreasing } \\
\text { prices; constant } \\
\text { marginal cost }\end{array}$ & $\begin{array}{l}\text { - Increase-decrease } \\
\text { - } \text { Decrease-increase } \\
\text { - Monotonically decreasing } \\
\text { - Monotonically increasing }\end{array}$ \\
\hline Our study & Two & $\begin{array}{l}\text { - } \quad \text { Unimodal bell-shaped } \\
\text { - } \quad \text { Bimodal chasm } \\
\text { - } \quad \text { Early dip followed by } \\
\text { bell-shaped } \\
\text { - } \quad \text { Exponential decline } \\
\text { (Major diffusion patterns } \\
\text { observed in the empirical } \\
\text { literature) }\end{array}$ & $\begin{array}{l}\text { Logarithmic } \\
\text { (Decreasing returns } \\
\text { to advertising is } \\
\text { observed in } \\
\text { empirical studies) }\end{array}$ & $\begin{array}{l}\text { External } \\
\text { influence, } \\
\text { within-segment } \\
\text { influence, and } \\
\text { cross-segment } \\
\text { influence of both } \\
\text { segments }\end{array}$ & Decreasing margin & $\begin{array}{ll}\text { - } & \text { Increase-decrease } \\
\text { - } & \text { Monotonically decreasing } \\
\text { - } & \text { songer period of medium } \\
& \text { spending, then decrease }\end{array}$ \\
\hline
\end{tabular}


Table 2: Diffusion Patterns Analyzed in this Study

\begin{tabular}{|c|c|c|c|l|l|}
\hline $\begin{array}{c}\text { Diffusion } \\
\text { pattern }\end{array}$ & $\begin{array}{c}\text { External } \\
\text { influence }\end{array}$ & $\begin{array}{c}\text { Within-segment } \\
\text { influence }\end{array}$ & $\begin{array}{c}\text { Cross-segment } \\
\text { influence }\end{array}$ & $\begin{array}{l}\text { Product } \\
\text { examples }\end{array}$ & $\begin{array}{l}\text { Studies that have empirically } \\
\text { shown this pattern }\end{array}$ \\
\hline $\begin{array}{c}\text { Unimodal bell- } \\
\text { shaped }\end{array}$ & Low & High & High & $\begin{array}{l}\text { Air conditioners, } \\
\text { clothes dryers }\end{array}$ & $\begin{array}{l}\text { Bass (1969) } \\
\text { Bass et al. (1994) }\end{array}$ \\
\hline Bimodal chasm & Low & High & Low & $\begin{array}{l}\text { Personal } \\
\text { computers, } \\
\text { camcorders }\end{array}$ & $\begin{array}{l}\text { Steffens \& Murthy (1992) } \\
\text { Goldenberg et al. (2002) } \\
\text { Van den Bulte \& Joshi } \\
(2007)\end{array}$ \\
\hline $\begin{array}{c}\text { Early dip } \\
\text { followed by } \\
\text { bell-shaped }\end{array}$ & $\begin{array}{c}\text { High for the early } \\
\text { market, low for } \\
\text { the main market }\end{array}$ & $\begin{array}{l}\text { Low for the early } \\
\text { market, high for } \\
\text { the main market }\end{array}$ & Low & Music CDs & $\begin{array}{l}\text { Moe \& Fader (2001) } \\
\text { Van den Bulte \& Joshi } \\
(2007)\end{array}$ \\
\hline $\begin{array}{c}\text { Exponential } \\
\text { decline }\end{array}$ & High & $\begin{array}{l}\text { Limited extent of social contagion } \\
\text { both within and across segments }\end{array}$ & $\begin{array}{l}\text { Fast moving } \\
\text { consumer goods, } \\
\text { movies }\end{array}$ & $\begin{array}{l}\text { Du \& Kamakura (2011) } \\
\text { Moretti (2011) }\end{array}$ \\
\hline
\end{tabular}

Table 3: Parameters Chosen For Different Diffusion Patterns

\begin{tabular}{|c|c|c|c|c|}
\hline Diffusion parameters & $\begin{array}{c}\text { Unimodal } \\
\text { bell-shaped }\end{array}$ & $\begin{array}{l}\text { Bimodal } \\
\text { chasm }\end{array}$ & $\begin{array}{l}\text { Early dip followed } \\
\text { by bell-shaped }\end{array}$ & $\begin{array}{l}\text { Exponential } \\
\text { decline }\end{array}$ \\
\hline External influence of the early market $\left(p_{1}\right)$ & 0.05 & 0.05 & 0.3 & 0.3 \\
\hline Within-segment influence of the early market $\left(q_{11}\right)$ & 0.15 & 0.8 & 0.01 & 0.05 \\
\hline $\begin{array}{l}\text { Cross-segment influence of the main market on the early } \\
\text { market }\left(q_{12}\right)\end{array}$ & 0.05 & 0 & 0 & 0.01 \\
\hline External influence of the main market $\left(p_{2}\right)$ & 0 & 0 & 0 & 0.1 \\
\hline $\begin{array}{l}\text { Cross-segment influence of the early market on the main } \\
\text { market }\left(q_{21}\right)\end{array}$ & 0.15 & 0.01 & 0.01 & 0.05 \\
\hline Within-segment influence of the main market $\left(q_{22}\right)$ & 0.35 & 0.5 & 0.5 & 0.01 \\
\hline Relative size of the early market $(\theta)$ & \multicolumn{4}{|c|}{$0.1-0.5$} \\
\hline Relative cost of targeting the early market $(\alpha)$ & \multicolumn{4}{|c|}{$1-3$} \\
\hline Adverting sensitivity of the early market $\left(\beta_{1}\right)$ & \multirow{2}{*}{\multicolumn{4}{|c|}{0.1}} \\
\hline Adverting sensitivity of the main market $\left(\beta_{2}\right)$ & & & & \\
\hline
\end{tabular}

Table 4: The Effect of Diffusion Parameters on the Optimal Time to Transition from the Early Market to the Main Market

\begin{tabular}{|l|c|c|c|}
\hline Diffusion parameter & Coefficient estimate & t-statistic & $p$-value \\
\hline External influence of the early market $\left(p_{1}\right)$ & -0.106 & -6.246 & $<0.001$ \\
\hline Within-segment influence of the early market $\left(q_{11}\right)$ & 0.102 & 6.020 & $<0.001$ \\
\hline Cross-segment influence of the main market on the early market $\left(q_{12}\right)$ & -0.007 & -0.439 & 0.660 \\
\hline External influence of the main market $\left(p_{2}\right)$ & \multicolumn{1}{|c|}{ Not applicable (variable set to zero) } \\
\hline Cross-segment influence of the early market on the main market $\left(q_{21}\right)$ & 0.059 & 3.503 & 0.001 \\
\hline Within-segment influence of the main market $\left(q_{22}\right)$ & -0.050 & -2.943 & 0.003 \\
\hline Relative size of the early market $(\theta)$ & 0.380 & 22.494 & $<0.001$ \\
\hline Relative cost of targeting the early market $(\alpha)$ & -0.455 & -26.916 & $<0.001$ \\
\hline Adverting sensitivity of the early market $\left(\beta_{1}\right)$ & 0.675 & 39.954 & $<0.001$ \\
\hline Adverting sensitivity of the main market $\left(\beta_{2}\right)$ & -0.149 & -8.803 & $<0.001$ \\
\hline
\end{tabular}




\section{References}

Bass, F. M. (1969). A New Product Growth Model for Consumer Durables. Management Science. 15, $215-$ 227.

Bass, F. M., Krishnan, T. V., Jain, D. C. (1994). Why the Bass Model Fits without Decision Variables. Marketing Science. 13(3), 203-223.

Beales, H. (2009). The Value of Behavioral Targeting. Available: http://networkadvertising.org/pdfs/ Beales NAI Study.pdf

Dockner, E., Jorgensen, S. (1988). Optimal Advertising Policies for Diffusion Models of New Product Innovations in Monopolistic Situations. Management Science. 34, 119-130.

Du, R. Y., Kamakura, W. (2011). Measuring Contagion in the Diffusion of Consumer Packaged Goods. Journal of Marketing Research. 48(Feb), 28-47.

Farahat, A., Bailey, M. (2012). How Effective is Targeted Advertising? WWW'12 Proceedings of the 21st International Conference on World Wide Web. 111-120.

Fruchter, G. E., Van den Bulte, C. (2011). Why the Generalized Bass Model Leads to Odd Optimal Advertising Policies. International Journal of Research in Marketing. 28, 218-230.

Goldenberg, J., Libai, B., Muller, E. (2002). Riding the Saddle: How Cross-Market Communications Can Create a Major Slump in Sales. Journal of Marketing. 66(2), 1-16.

Green, H. (2008). Google: Harnessing the Power of Cliques. BusinessWeek. (October 6), 50.

Horsky, D., Simon, L. S. (1983). Advertising and the Diffusion of New Products. Marketing Science. 2(1), 117.

Iyer, G., Soberman, D., Villas-Boas, J. M. (2005). The Targeting of Advertising. Marketing Science. 24(3), 461-476.

Krishnan, T. V., Bass, F. M., Jain, D. C. (1999). Optimal Pricing Strategy for New Products. Management Science. 45(12), 1650-1663.

Krishnan, T. V., Jain, D. C. (2006). Optimal Dynamic Advertising Policy for New Products. Management Science. 52(12), 1957-1969.

Lodish, L. M., Abraham, M., Kalmenson, S., Livelsberger, J., Lubetkin, B., Richardson, B., et al. (1995). How TV-advertising works: A meta-analysis of 389 real-world split cable TV-advertising experiments. Journal of Marketing Research, 32, 125-139.

Mahajan, V., Muller, E. (1998). When is it Worthwhile Targeting the Majority Instead of the Innovators in a New Product Launch? Journal of Marketing Research. 35, 488-495.

Moe, W. W., Fader, P. S. (2001). Modeling Hedonic Portfolio Products: A Joint Segmentation Analysis of Music Compact Disc Sales. Journal of Marketing Research. 38, 376-385.

Moore, G. A. (1991). Crossing the Chasm. Harper Business, New York.

Moretti, E. (2011). Social Learning and Peer Effects in Consumption: Evidence from Movie Sales. Review of Economic Studies. 78, 356-393.

Putsis, W. P. Jr., Balasubramaniam, S., Kaplan, E. H., Sen, S. K. (1997). Mixing Behavior in Cross-Country Diffusion. Marketing Science. 16, 354-369.

Robehmed, N. (2013). The Marketing Magic of Klout Perks. Forbes. Available online at http://onforb.es/ $154 \mathrm{j} 9 \mathrm{CY}$

Simon, J. L., Arndt, J. (1980). The Shape of the Advertising Response Function. Journal of Advertising Research. 20(4), 11-30.

Steffens, P. R., Murthy, D. N. P. (1992). A Mathematical Model for New Product Diffusion: The Influence of Innovators and Imitators. Mathematical and Computer Modelling. 16(4) 11-26.

Teng, J.T., Thompson, G. L. (1983). Oligopoly Models for Optimal Advertising. Management Science. 29, 1087-1101.

Thompson, G. L., Teng, J. T. (1984). Optimal Pricing and Advertising Policies for New Product Oligopoly Models. Marketing Science. 3, 148-168.

Vakratsas, D., Ambler, T. (1999). How Advertising Works? What Do We Really Know? Journal of Marketing. 63(1), 26-43.

Van den Bulte, C., Joshi, Y. V. (2007). New Product Diffusion with Influentials and Imitators. Marketing Science. 26(3), 400-421.

Vascellaro, J. E. (2011). TV's Next Wave: Tuning In to You. Wall Street Journal. March 7. 